\title{
Educação no Trabalho na Atenção Primária à Saúde: interfaces entre a educação permanente em saúde e o agir comunicativo'
}

\author{
Work Education in Primary Health Care: interfaces between \\ permanent education in health and the communicative \\ action
}

\author{
Jaqueline Alcântara Marcelino da Silva \\ Mestre em Enfermagem. Doutoranda do Programa de Pós-Gradua- \\ ção em Gerenciamento em Enfermagem da Escola de Enfermagem \\ da USP (EEUSP). Enfermeira especialista do Laboratório de Ensino \\ do Departamento de Orientação Profissional da EEUSP. \\ Endereço: Av. Dr. Enéas Carvalho de Aguiar, 419, Cerqueira César, \\ CEP 05403-000, São Paulo, SP, Brasil. \\ E-mail: jaqueline.alcaœusp.br \\ Marina Peduzzi \\ Professor Associado do Departamento de Orientação Profissional \\ da EEUSP. \\ Endereço: Av. Dr. Enéas Carvalho de Aguiar, 419, Cerqueira César, \\ CEP 05403-000, São Paulo, SP, Brasil. \\ E-mail: marinapeœusp.br \\ I Parte da dissertação de mestrado do primeiro autor, Silva JAM. \\ Análise das atividades educativas de trabalhadores de saúde na \\ atenção básica: concepções de educação no trabalho, levanta- \\ mento de necessidades, público participante e resultados espera- \\ dos [dissertação]. São Paulo: Escola de Enfermagem, Universidade \\ de São Paulo; 2009. \\ Apoio da Fundação de Amparo à Pesquisa do Estado de São \\ Paulo (FAPESP) e da Rede de Observatório em Recursos Humanos \\ da Organização Pan-Americana de Saúde (OPAS)/ Ministério da \\ Saúde (MS).
}

\section{Resumo}

O trabalho em saúde e a educação no trabalho constituem-se com uma dupla dimensão - ação instrumental e intersubjetividade. Objetivo: Analisar as concepções de educação que fundamentam as atividades educativas de trabalhadores da saúde na atenção primária. Método: Estudo de abordagem qualitativa realizado em duas unidades básicas de saúde do município de São Paulo, por meio de entrevista semiestruturada gravada com 36 informanteschave, representativos de cada categoria profissional dos serviços, incluindo o segmento gerencial e o de trabalhadores da saúde. Os dados foram analisados com a técnica de análise de conteúdo temática com base no quadro teórico: processo de trabalho em saúde, teoria do agir comunicativo, educação continuada (EC), educação permanente em saúde (EPS) e integralidade, os quais permitiram a construção das categorias empíricas: educação instrumental/tradicional e educação comunicativa/emancipatória. Resultados: Os resultados mostram o predomínio da concepção de educação no trabalho como construção coletiva do saber a partir da realidade de trabalho, pertinentes à EPS que se pretende instituir para a mudança das práticas e do modelo assistencial biomédico. Contudo, alguns depoentes expressam uma concepção de educação instrumental com ênfase em ações técnicas e de atualização do saber, que se aproxima da EC. Conclusão: Os resultados evidenciam a convivência das duas concepções de educação de trabalhadores - instrumental e comunicativa com o predomínio da segunda, que mostra a capilaridade da política de EPS entre os trabalhadores de saúde 
das UBS e a necessidade de aprofundar o debate para consolidar a prática educativa no cotidiano de trabalho.

Palavras-chave: Educação permanente em saúde; Educação continuada; Trabalho; Recursos humanos em saúde; Atenção primária à saúde.

\section{Abstract}

Health work and work education are a double dimension - instrumental action and intersubjectivity. Objective: To analyze the conceptions of education that support educational activities of health care workers in Primary Health Care. Method: This qualitative study was conducted in two primary health care units (PHCU) in São Paulo, through semi-structured interviews with 36 key informants representing each professional category, including managers and health care workers. Data were analyzed based on thematic content analysis and on the theoretical framework: the healthcare work process, theory of communicative action, continuing education (CE), permanent education in health (PEH) and integrality (comprehensive approach), which allowed the construction of the empirical categories: instrumental/traditional education and communicative/emancipatory education. Results: The results show the prevailing notion of work education as a collective construction of knowledge from the reality of work, relevant to the PEH that is intended to be introduced in order to change the practices and the biomedical health care model. However, some interviewed subjects expressed an instrumental conception of education that emphasizes technical actions and knowledge updating, which is closer to CE. Conclusion: Results show the coexistence of the two conceptions of workers' education: instrumental and communicative, with the predominance of the second one, which shows the reach of the PEH policy among the health workers of PHCU and the need for deepening the discussion to consolidate educational practice in daily work.

Keywords: Permanent education in health. Continuing education. Work. Healthcare human resources. Primary Health Care. 


\section{Introdução}

Neste estudo, parte-se do pressuposto de que a educação e o trabalho são práticas sociais, portanto estão articulados e reconfiguram um ao outro. Ao tomar como objeto de reflexão a educação de trabalhadores inseridos em serviços, ou seja, a educação no trabalho em saúde, entende-se que a educação é parte do trabalho.

Localizado no setor terciário do modo de produção capitalista, o trabalho em saúde faz parte da produção de serviços. "O serviço é trabalho em processo, e não o resultado da ação do trabalho; por esta razão elementar não se produz um serviço, e sim se presta um serviço" (Meirelles, 2006, p. 134). Caracterizado pela interpretação das necessidades dos usuários, o trabalho em serviços refere-se a um processo interativo entre prestador e usuários em vez de desenvolver um produto material. Dessa forma, o produto do processo de trabalho em serviços é intangível e inestocável, pois a produção e o consumo são simultâneos no tempo e espaço (Meirelles, 2006).

O trabalho em saúde tem as características da produção em serviço, com marcante complexidade, sobretudo pela intersubjetividade intrínseca ao processo de trabalho e pelas múltiplas dimensões de seus objetos de intervenção (Peduzzi, 2002). Cabe destacar que pode ser entendido como trabalho reflexivo (Offe, 1995), uma vez que as necessidades trazidas ou sentidas pelos usuários dos serviços são interpretadas pelos trabalhadores segundo regras técnico-científicas aplicadas à especificidade de cada situação (Offe, 1995; Peduzzi, 2002).

Assim, considera-se a dimensão microssocial do processo de trabalho em saúde que diz respeito ao exercício cotidiano do trabalho, aos sujeitos e à intersubjetividade, ou seja, à prática dos trabalhadores no cotidiano da produção e do consumo de serviços de saúde. Esta, por sua vez, remete à inserção do processo de trabalho na dinâmica macrossocial do trabalho humano, que se refere a aspectos das estruturas sociais e históricas que o constituem e a ele se articulam (Pires e col., 2004).

No plano microssocial do cotidiano de trabalho a discussão sobre o processo de trabalho não pode ser reduzida à ação instrumental. A intersubjetividade é uma dimensão presente no trabalho na qual os sujeitos podem configurar práticas comunicativas.

$\mathrm{O}$ arcabouço técnico-científico fundamenta a ação instrumental cuja execução envolve a escolha racional dos meios que serão utilizados a partir do critério de controle da eficiência e das alternativas de comportamento. Na busca do êxito técnico como resultado, as regras apreendidas da ação instrumental no trabalho configuram o desenvolvimento de habilidades que capacitam os sujeitos para resolver problemas no cotidiano do trabalho (Habermas, 1994).

Contudo, vale destacar que a racionalidade instrumental técnico-científica não recobre o complexo leque de necessidades de saúde dos usuários e população, visto que se construiu, intersubjetivamente, o reconhecimento da saúde como direito orientado à integralidade. Nesse sentido, os trabalhadores executam ações que vão além da recuperação da saúde e contemplam a prevenção de agravos e a promoção da saúde para o que precisam recorrer a outras ferramentas de trabalho além do arsenal técnico-científico.

Adota-se uma abordagem que concebe o trabalho e a educação no trabalho constituídos intrinsecamente por uma dupla dimensão: ação instrumental e interação social. Enquanto ação produtiva, o trabalho é ação instrumental, regida pela racionalidade técnico-científica com finalidade determinada, ação dirigida a um fim. Como interação social, o trabalho refere-se à ação comunicativa, intersubjetiva, na qual os sujeitos envolvidos - trabalhadores, gerentes, gestores e usuários - buscam alcançar algum grau de entendimento e coordenação das ações (Schraiber e col., 1999). Assim, para o estudo da educação no trabalho em saúde consideram-se tanto os elementos constitutivos do processo de trabalho quanto a dinâmica intersubjetiva na qual é possível a comunicação/interação pautada na argumentação.

De acordo com Habermas, o trabalho possui uma racionalidade científica e técnica, que consiste na escolha adequada de meios para atingir determinados fins; contudo, para as esferas de decisão deveria entrar em jogo também a racionalidade comunicativa. $O$ agir humano, portanto, pode ser analisado considerando as duas dimensões referidas, o trabalho como ação racional de caráter técnico-científico e a 
interação comunicativa intersubjetiva (Habermas, 1994; Aragão, 2002).

No tocante à interação comunicativa considerase a teoria do agir comunicativo de Habermas que inclui a situação de fala, a aplicação da linguagem, seu contexto, as pretensões de validez e os papéis do diálogo. Habermas considera que a linguagem possui inúmeras funções: a cognitiva para o conhecimento intersubjetivo das normas sociais, a apelativa para dirigir solicitações; a imperativa para que determinado resultado seja alcançado; e a expressiva para tornar conhecidas experiências pessoais. Ao utilizar as diferentes funções da linguagem, os interlocutores buscam estabelecer três diferentes tipos de pretensões de validade da comunicação intersubjetiva por meio da argumentação: correção normativa, verdade proposicional e autenticidade expressiva das informações (Habermas, 2001).

A verdade proposicional é aceitável como expressão da realidade ou certezas compartilháveis; a correção normativa possibilita uma relação interpessoal legítima ao compartilhar aspectos éticos, políticos e morais do enunciado; e a autenticidade expressiva remete ao estabelecimento de uma relação de confiança e sinceridade com efetiva comunicação entre os interlocutores (Habermas, 2001).

As pretensões de validade da comunicação intersubjetiva apoiam-se em três mundos: o mundo objetivo ou estado das coisas, o social ou normas sociais e o subjetivo. A ação comunicativa pode ocorrer nessas três dimensões articuladas pelo mundo da vida (Artman, 2001; Aragão, 2002).

O mundo da vida é o espaço de entendimento dos sujeitos envolvidos na comunicação interativa cotidiana e envolve três elementos estruturais: a cultura, a sociedade e a personalidade. Habermas considera uma dialética presente entre o mundo da vida e os sistemas da sociedade moderna e aponta um avanço da racionalidade técnico-científica ou dos sistemas sobre o mundo da vida, ou seja, uma colonização das ações instrumentais em esferas da vida que deveriam estar orientadas pelo agir comunicativo (Habermas, 2001).

$\mathrm{Na}$ ação comunicativa argumentativa proposta por Habermas, as pessoas interagem em busca de consenso livre de coação quando algo é problematizado por meio do diálogo. 0 discurso, uma das formas de comunicação ou da fala, que compõe o 'agir comunicativo' ou 'interação' busca pretensões de validade entre opiniões e normas sociais, por isso pode ser reconhecido como um discurso intersubjetivo e argumentativo no qual prevalece o melhor argumento que possibilita a origem de um acordo (Aragão, 2002; Habermas, 2001).

Com a primazia da lógica instrumental no trabalho em saúde, as necessidades vividas e sentidas pelos usuários deixam de ser analisadas mediante valores éticos e políticos, devido ao foco em interesses instrumentais que reduzem a abordagem aos problemas técnicos.

A lógica instrumental sustenta o trabalho em saúde pautado na fisiopatologia para o diagnóstico e obtenção de sucessos no tocante à restauração biológica; contudo, considerar a experiência vivenciada pelos usuários e os limites da intervenção clínica requer adotar uma postura ativa de interação dialógica para a construção ampliada do cuidado em saúde (Rocha e Almeida, 200o).

A educação permanente em saúde (EPS) é realizada no âmbito do trabalho e destina-se a refletir sobre esse processo considerando as necessidades de saúde dos usuários/população. É reconhecida como trabalho que articula a atenção à saúde, a formação, a gestão e o controle social para a transformação das práticas de saúde e da organização no trabalho (Merhy e col., 2006).

A EPS tem o objetivo de constituir uma rede de ensino-aprendizagem no exercício de trabalho no SUS, com a sua recomposição na direção das necessidades da população/usuários como cidadãos de direitos. Afinal, no setor da saúde ocorre uma concentração do saber em áreas técnicas de profissionais específicos, que anulam as realidades locais em prol do conhecimento técnico que impõe uma linha de prescrições ao trabalho (Ceccim, 2005a, 2005b). Portanto, faz-se necessário ampliar as possibilidades de respostas para além do normatizado, por meio da interação intersubjetiva, em direção às necessidades de saúde dos usuários/população.

Nesse sentido, a EPS poderia representar uma possibilidade de resgate da ação comunicativa intersubjetiva em espaços do trabalho nos quais predominam a racionalidade instrumental e a educação continuada (EC) direcionada para o desenvolvimento 
da racionalidade técnico-científica em espaços de atualização profissional para manter a normatividade das ações de saúde.

A literatura a respeito da EC mostra o enfoque desse conceito na atualização e reciclagem dos trabalhadores da saúde com centralidade na execução de procedimentos técnicos. Girade e col. (2006); Bezerra (2000); Davim e col. (1999) apontam para a importância de o trabalhador manter-se atualizado frente às mudanças técnico-científicas com a finalidade de atualizar o conhecimento.

A busca do conhecimento dos modos de emancipação de qualquer perspectiva de coação teórica ou prática pode ser relacionada ao papel da educação no contexto do trabalho por constituir espaços para reflexão, emprego da criatividade e inovação para reconfigurar as práticas de saúde. Assim, o agir comunicativo será fundamental para possibilitar avanços na direção emancipatória por meio de uma atitude consensual orientada ao entendimento.

Na perspectiva de Paulo Freire (2005), a educação constitui um processo de mediação emancipatória que permite a formação do pensamento crítico reflexivo, construído, problematizado e não apenas aplicado e consumido, tal como na 'educação bancária' que fornece as respostas prontas ao transmitir o saber. A postura crítico reflexiva possibilita a busca em profundidade para a análise dos problemas.

A problematização das práticas de saúde no trabalho possibilita a compreensão e busca de nexos no processo de trabalho, cuja compreensão crescente tende a se tornar reflexiva. Para Feuerwerker (2005), o engajamento dos trabalhadores na ação de repensar as práticas e atuar positivamente mediante o diálogo é estimulado ao reconhecer seus conhecimentos prévios, aspecto fundamental à EPS.

Essa modalidade educativa propõe a integração dos processos educativos de trabalhadores às experiências cotidianas dos serviços, a mudança das estratégias pedagógicas ao tomar as práticas concretas como fonte de conhecimento, a concepção de trabalhadores da saúde como agentes críticos e reflexivos com capacidade de construir o conhecimento e propor ações alternativas para a solução de problemas, e o trabalho em equipe como modalidade de organização do trabalho (Souza e Roschke, 2003).
O trabalho em equipe pode ser considerado uma condição da integralidade, pois requer a articulação de diferentes saberes em um processo de trabalho aberto com novas possibilidades de construção não previstas anteriormente em protocolos de atenção à saúde (Ramos, 2009).

A prática dialógica da educação no trabalho corresponde à proposta da integralidade ao favorecer o reconhecimento dos saberes dos usuários e trabalhadores sobre suas situações concretas de vida e processos saúde-doença-cuidado. Contribui para uma apreensão mais abrangente das necessidades de saúde dos sujeitos e sensibiliza-os à ação educativa (Alves, 2005).

A integralidade como eixo norteador das capacitações em saúde possibilita a articulação dos saberes e práticas interprofissionais a partir de um conceito ampliado de saúde que respeita a subjetividade do usuário mediante o acolhimento e a responsabilização para superar as práticas centradas em procedimentos com foco na doença (Ceccim e Feuerwerker, 2004; Ceccim, 2005a; Feuerwerker, 2005).

Situada entre os princípios do SUS, a integralidade volta-se para a articulação de ações de promoção, prevenção e recuperação da saúde. Busca atender as necessidades dos usuários/população de modo ampliado para além do foco reduzido à doença ao tomar o contexto social, econômico e cultural dos usuários. Lógica que pode contribuir para reorganizar o processo de trabalho nos serviços de saúde (Mattos, 2004) por distanciar-se do modelo assistencial biomédico hegemônico que reitera uma visão fragmentada da atenção à saúde e distante dos usuários/população.

A atenção primária à saúde (APS) tem como foco as necessidades de saúde da população/usuários e busca se organizar na perspectiva da integralidade com a possibilidade do desenvolvimento de espaços de interação nos processos de trabalho em saúde. De acordo com Pinheiro (2006), a APS é concebida como uma construção coletiva, que ganha forma e expressão no encontro com os diferentes sujeitos implicados na produção dos cuidados à saúde.

A contribuição desse estudo reside no potencial do debate acerca da articulação entre trabalho em saúde e educação no trabalho como parte das estratégias para a transformação das práticas de saúde 
no contexto da APS. Assim, tem como objetivo analisar as concepções de educação que fundamentam as atividades educativas de trabalhadores da saúde na APS.

\section{Metodologia}

Realizou-se um estudo de abordagem qualitativa com caráter compreensivo e analítico. A pesquisa qualitativa caracteriza-se pela busca de compreensão da realidade da vida social compartilhada pelos indivíduos. As palavras dos participantes são autênticas e se convertem em resultados empíricos da investigação dos quais emerge a 'teoria' que permite ao investigador compreender a explicação do fenômeno no mundo social proporcionando um sentido à realidade encontrada que surge nos conceitos e nas categorias dos próprios dados (Cook e Reichardt, 2000).

Selecionaram-se duas unidades básicas de saúde (UBS) pertencentes a uma Coordenadoria Regional de Saúde do município de São Paulo. As unidades foram selecionadas a partir da identificação da tradição dessas UBS no desenvolvimento de atividades educativas para os trabalhadores de saúde, segundo os resultados do projeto de pesquisa principal $^{2}$ ao qual este estudo está vinculado. Os referidos resultados foram divulgados em publicação recente (Peduzzi e col., 2009).

A primeira UBS $(A) 3$ do estudo possui aproximadamente 120 trabalhadores dos quais 100 estão vinculados a uma universidade pública e 20 a uma organização social de saúde (OSS), contratados para a Estratégia de Saúde da Família (ESF). A segunda UBS (J) possui aproximadamente 110 trabalhadores, 50 vinculados à Secretaria Municipal de Saúde (SMS) de São Paulo e 6o trabalhadores da ESF distribuídos em cinco equipes de saúde da família, contratados por uma OSS. Em ambas as unidades destaca-se o potencial dos trabalhadores e gerentes para o ensino de estudantes de graduação e pós-graduação da área da saúde por se constituírem em campos de estágio há mais de cinco anos.

A pesquisa atendeu às exigências da Resolução n. 196/96 do Conselho Nacional de Saúde (Brasil, 1996), com aprovações dos Comitês de Ética em Pesquisa da Escola de Enfermagem da USP e da SMS de São Paulo.

Mediante a assinatura do termo de consentimento livre e esclarecido, 36 sujeitos participaram do estudo, indicados pelos gerentes das UBS como informantes-chave, representativos de cada categoria profissional inserida no serviço incluindo o segmento gerencial e de trabalhadores da saúde.

Entrevistaram-se cinco trabalhadores de nível técnico auxiliar (quatro auxiliares administrativos e um técnico de informática), 21 trabalhadores da dimensão assistencial (dois de cada categoria profissional a seguir: dentistas, médicos, psicólogos, educadores; e um trabalhador de cada uma das seguintes categorias: fisioterapeuta, fonoaudiólogo, farmacêutico, assistente social e terapeuta ocupacional, quatro auxiliares de enfermagem, dois auxiliares de consultório dentário e dois agentes comunitários de saúde), dez trabalhadores da dimensão gerencial (três médicos, dois enfermeiros, um de cada função especificada a seguir: fonoaudióloga, técnico administrativo, auxiliar técnico administrativo) e dois gerentes centrais das UBS (enfermeiro e médico sanitarista).

As entrevistas foram gravadas e integralmente transcritas, totalizando aproximadamente 50 horas de gravação, com duração média de uma hora e vinte minutos em cada entrevista, com mínima de trinta minutos e máxima de duas horas e trinta minutos. Os entrevistados foram identificados com um número, com a categoria profissional e a letra $\mathrm{T}$ ou a letra G, que indicam trabalhadores e gerentes,

\footnotetext{
2 Esta investigação está vinculada ao projeto de pesquisa principal - Análise dos processos educativos de trabalhadores e equipes de saúde: características, levantamento de necessidades e resultados esperados. Integra-se à linha de pesquisa Gerenciamento de Recursos Humanos em Saúde e Enfermagem, do Programa de Pós-Graduação em Gerenciamento de Enfermagem da Escola de Enfermagem da Universidade de São Paulo e ao Grupo de Pesquisa do Diretório do Conselho Nacional de Desenvolvimento Científico e Tecnológico (CNPq), Gestão de Recursos Humanos da Perspectiva do Processo de Trabalho em Saúde e Enfermagem liderado pela Profa. Dra Marina Peduzzi, orientadora do presente estudo.

3 A identificação da primeira UBS com a letra A e da segunda UBS com a letra J é correspondente à identificação dada a esses serviços na pesquisa principal.
} 
respectivamente. Foi utilizado um roteiro guia para coletar inicialmente informações sobre o perfil do trabalhador: cargo/função, formação, categoria profissional, tempo de trabalho no serviço e questões específicas do roteiro do estudo relacionadas à concepção de educação de trabalhadores, no respectivo estabelecimento de saúde: 'O que você pensa a respeito de atividades educativas para trabalhadores de saúde inseridos nesse serviço? Relate situações de educação no trabalho que vivenciou e considerou interessante. Como deveriam ser desenvolvidas as atividades educativas de trabalhadores nos serviços de saúde?'.

Os dados foram analisados com a técnica de análise de conteúdo temática (Bardin, 2009) à luz do quadro teórico: processo de trabalho em saúde, educação continuada (EC), educação permanente em saúde (EPS), teoria do agir comunicativo e concepção de integralidade. Realizou-se a leitura flutuante e repetida de cada entrevista, a vertical para obter a síntese dos depoimentos, seguida da leitura horizontal para identificar as concepções de educação presentes nos relatos e análise transversal para identificar contradições e semelhanças (Schraiber, 1995). A última foi realizada de modo conjunto, sem distinção entre os depoimentos dos dois serviços pesquisados, porque com a realização da análise vertical das entrevistas não se observou diferença expressiva nos relatos de ambos os serviços.

\section{Resultados e Discussão}

A análise do universo de relatos à luz do quadro teórico apresentado resultou na construção de três categorias empíricas relacionadas ao objetivo de identificar as concepções de educação no trabalho dos trabalhadores e gerentes entrevistados no contexto da atenção primária.

\section{Quadro I - Categorias empíricas construídas no universo de relatos entre trabalhadores e gerentes sobre edu- cação no trabalho}

I. A educação constitui-se em um processo de construção coletiva do saber entre os trabalhadores a partir da realidade de trabalho.

2. A educação é inerente à organização do trabalho em saúde.

3. Atividades educativas de trabalhadores para transmitir ou atualizar informações.

A educação constitui-se em um processo de construção coletiva do saber entre os trabalhadores a partir da realidade de trabalho

A concepção de educação como construção coletiva contextualizada na realidade de trabalho é consenso para a maioria dos entrevistados, portanto predomina na realidade empírica investigada. Essa representação pode ser denominada comunicativa/ emancipatória devido ao seu caráter voltado para a promoção dos sujeitos partícipes do processo de trabalho, trabalhadores, usuários e gerentes de serviços de saúde.

Diferentemente do processo de transferência de conhecimento, educar na perspectiva emancipatória é criar possibilidades para que o educando participe da produção do saber. Trata-se de um processo recíproco de ensinar e aprender do homem como ser histórico e inacabado, pois aprendendo social e historicamente o homem descobre a atividade de ensinar. 0 ensino bancário baseado na transferência de conteúdos é conduzido com autoritarismo, o que prejudica a aprendizagem e a criatividade do educando e do educador. A prática educativa crítica envolve o movimento dinâmico do fazer e pensar sobre o fazer com a reflexão crítica sobre a prática atual que pode desenvolver mecanismos de mudança (Freire, 2005).

Os entrevistados apontaram a importância de promover a educação dos trabalhadores da saúde contextualizada à sua realidade de trabalho em um processo de construção coletiva do saber.

Não adianta você convidar uma pessoa para falar de medicamentos que o usuário não vai adquirir. Não serve para nada um curso deste entendeu? Ou o enfermeiro participar de um evento que não esteja relacionado com o espaço público, para ele extrapolar e poder ampliar e articular aquilo com a realidade. Seria melhor 
se fosse construído de acordo com a realidade, fazendo a construção do conhecimento junto! Porque depois sozinho é difícil para pessoa fazer este processo ( $\mathrm{G}_{5}$ - enfermeiro).

Alguns depoentes também reconhecem a importância de estabelecer a relação teórico-prática na produção do conhecimento mediante a construção do saber, com a participação dos trabalhadores, para evitar a centralização do saber, pois esta poderá ampliar o poder daqueles que o detêm. De acordo com Lopes (2001), o poder pode ser entendido como uma característica ou condição de determinados trabalhadores, que é expresso nas relações de trabalho em zonas de incerteza/indeterminação sobre as intervenções de saúde nos serviços. Assim, um agente terá mais poder quando exercer domínio e estabelecer algum grau de condicionamento sobre a ação dos outros, o que pode estar relacionado à posição que ocupa no serviço e ao seu lugar na divisão técnica e social do trabalho.

Na educação, por exemplo, a teoria e a prática não andam juntas, é ruim, só a teoria ou só a prática, as duas têm que andar juntas. Acredito firmemente que o conhecimento deve ser construído e adquirido com a participação de educadores $e$ educandos, numa relação mútua. Cada educador cresce a cada ação de educação que ele faz. Se ele estiver impermeável a crescer, ele já é um conservador. A educação é um processo de construção que envolve os dois, educador e educando. É um processo em que o poder deve estar na relação $e$ não em um dos polos, nem aqui nem lá. O poder deve emanar do próprio conhecimento construído [...] Eu aprendi aqui no serviço que a participação é fundamental e que a transparência constrói. $O$ conhecimento é a moeda de poder, então se buscarmos uma igualdade de poder, tanto no poder médico - paciente ou enfermagem - paciente, a gente busca diminuir esse poder o máximo possivel. Se eu tenho um discurso desse tipo em relação ao usuário, não posso deixar de ter em relação a nós, trabalhadores, como uma posição política de dividir poder, nivelar o profissional de saúde com o usuário de forma que as coisas não viessem de cima para baixo (T23 - auxiliar de enfermagem).
Os relatos mostraram que a construção do saber deve articular saberes de gerentes e trabalhadores, afinal a eficácia da atividade educativa no trabalho requer a participação e o envolvimento do trabalhador. Entende-se que, quando se parte da realidade do sujeito envolvido na aprendizagem, ocorre a aprendizagem significativa, aspecto que se aproxima da concepção de EPS, assim como a problematização, a participação e a reflexão crítica. Contudo, alguns entrevistados apontam também para a necessidade de desenvolver atividades tradicionais para transmitir ou atualizar informações necessárias para a rotina de trabalho.

Os depoentes reforçam a importância de atividades educativas pautadas tanto em concepções emancipatórias como em tradicionais. Nesse sentido, entende-se que é necessário haver uma discussão do saber instrumental necessário para o desenvolvimento das ações técnicas com resolubilidade. Como esse saber está baseado em preceitos técnico-científicos estabelecidos, o preparo dos trabalhadores volta-se ao rigor que deve estar presente em procedimentos já consolidados e podem ser veiculados em atividades educativas tradicionais. Os saberes profissionais são considerados um recurso fundamental na execução de procedimentos técnicos e requerem capacitação técnica na vertente tradicional. Contudo, alguns relatos também expressam que a construção de um modelo pautado na integralidade requer a reflexão sobre o trabalho cotidiano que se aproxima da vertente emancipatória da EPS. Assim, as atividades educativas de trabalhadores da saúde podem ser compostas de ações pautadas tanto na concepção emancipatória/comunicativa, participativa de educação, quanto na tradicional/instrumental, o que expressa a pertinência de duas modalidades de educação no trabalho, EPS e EC.

Para você poder transformar o que você faze propor uma ação transformadora do outro, você também tem que estar em transformação, em revisão de algo. Senão fica meio difícil! Não é o tempo todo que as práticas de saúde vão estar priorizando essa transformação. Vai ter uma série de conhecimentos que se conservam, que vão sendo transmitidos [...] mas até para isso se dar de uma maneira ágil, dinâmica, satisfatória, de comum acordo entre as necessidades de quem 
é o provedor e quem está recebendo algum cuidado [...] Nas situações de recuperação, eu acho que essa tecnologia, esse aspecto do saber, tem que ser transmitido de uma maneira mais ágil. Então, esse aspecto de transformação de caráter educativo terá um espaço menor. Estou imaginando a questão das vacinas e dos curativos, então tem que ter espaço para essa transmissão. Mas de qualquer forma, o sujeito tem que estar se sentindo renovado em algum espaço do trabalho dele. Estou imaginando um trabalho de UTI, onde a interação é mínima, as pessoas estão sob aparelhos, neste caso é necessário que o trabalhador em treinamento e supervisão, nos espaços educativos planejados, considere que ocorrerá transmissão de técnicas importantíssimas, essenciais, para as quais o trabalhador tem que estar pronto, e satisfeito, e valorizando tudo que ele está fazendo. Agora, para as questões de trabalho de promoção e prevenção, você vai estar construindo essas técnicas, então você também precisa estar mais confiante a respeito do impacto que aquilo vai ter [...] Diferentemente do impacto no trabalho de um curativo (T17 - terapeuta ocupacional).

Nas atividades educativas comunicativas/emancipatórias o trabalhador coloca-se como agente ativo do aprendizado em um processo de construção compartilhada do saber. Uma das características do trabalho em saúde é a interdependência entre os diferentes processos de trabalho especializados constituídos com a divisão técnica e social do trabalho. Assim, é possível observar a relação entre as ações educativas de trabalhadores e os respectivos processos de trabalho, bem como o trabalho em equipe que consiste em uma possibilidade de recomposição dos diferentes trabalhos especializados (Peduzzi, 2007). Segundo Peduzzi (2001, p. 106), “a recomposição requer a articulação das ações, a interação comunicativa dos agentes e a superação do isolamento dos saberes".

Embora a divisão técnica e social do trabalho produza o parcelamento e a fragmentação das práticas de saúde, no trabalho coletivo há uma interdependência e complementaridade entre os trabalhos especializados de modo que o trabalho de cada área profissional complementa o trabalho das demais e pode ocorrer sua articulação em torno de uma mesma finalidade (Lima e Almeida, 1999). Assim, a EPS também deveria contemplar os espaços interprofissionais por meio da interação entre profissionais de diferentes áreas.

A interação refere-se ao agir comunicativo regido por expectativas comportamentais que devem ser entendidas por pelo menos dois sujeitos para a construção de consensos e a coordenação das ações (Habermas, 2001). Mas a educação no trabalho vai além da interação entre trabalhadores, gerentes e usuários, pois também contempla o conjunto de saberes técnico-científicos que fundamentam um conjunto de ações de saúde consagradas na atenção às necessidades dos usuários.

Nesse sentido, o caráter interativo do trabalho em saúde remete também ao papel do trabalhador como mediador entre as necessidades dos usuários e os saberes estruturados que fundamentam as intervenções técnicas para adequá-las à especificidade e singularidade de cada demanda. Como apontado anteriormente, o trabalho em serviços depende de habilidades de interpretação e processamento de informações para atender aos usuários.

\section{A Educação é Inerente à Organização do Trabalho em Saúde}

A organização do trabalho é um dos principais aspectos do trabalho gerencial, por isso, na análise conjunta dos relatos de trabalhadores e gerentes sobre as concepções de educação no trabalho, a presente categoria predomina nos relatos de gerentes devido ao aprofundamento e acúmulo de reflexões que estes têm sobre o tema. Gerentes e trabalhadores entrevistados consideram que as atividades educativas são elemento intrínseco da organização do trabalho em saúde e podem ocorrer em espaços informais e formais, com reuniões previstas no cotidiano do trabalho. Esses momentos possibilitam a discussão contínua das práticas de saúde, sua organização, finalidades e especificidades para atender as necessidades educativas dos trabalhadores vinculadas à sua realidade concreta no serviço.

Então, me parece que umas das grandes características desse serviço, e disso eu me orgulho muito, é a possibilidade de o trabalho ser discutido 
continuamente. Então você tem situações mais formais de temas que são arrolados durante o ano, ou grupos de trabalho que se encontram. Você tem grupos de trabalho onde as pessoas estão discutindo as questões dos programas $e$ aquilo é uma coisa mais formal dentro do início de uma linha de desenvolvimento com meio, fim e avaliação ( $\mathrm{G}_{1}$ - médico).

É importante que a educação esteja incorporada no cotidiano de trabalho em saúde por sua característica de serviço cujo trabalho se realiza por meio do encontro entre sujeitos - trabalhadores e usuários.

0 trabalho em saúde é caracterizado pela intersubjetividade e também pela imprevisibilidade e incerteza. O caráter imprevisível do processo de trabalho nos serviços de saúde está relacionado à variedade de eventos e complexidades presentes no processo saúde-doença e à intersubjetividade nas relações entre trabalhadores-usuários e entre os trabalhadores. "Imprevisível e subjetivo são termos utilizados pelos especialistas para explicar as dificuldades de se avaliar a factibilidade", ou seja, as possibilidades de modelos de organização de serviços de saúde (Pinheiro e Luz, 2003, p. 8).

A intersubjetividade no trabalho em saúde é uma possibilidade de ampliar os espaços de reflexão sobre as práticas de saúde e de educação dos trabalhadores da saúde para configurar ações que não sejam reduzidas à execução de técnicas. Por isso, é importante que haja espaços de discussão, construção de consensos, acordos por meio da ação de combinar e recombinar estratégias para o planejamento das ações educativas dos trabalhadores para possibilitar resultados da atenção à saúde. A busca de consensos entre os sujeitos envolvidos no processo de trabalho configura um meio de negociação direcionada a determinado fim, por isso o trabalho em saúde e a educação no trabalho compõem ação instrumental e ação comunicativa.

Aragão (2002), considera que a negociação requer a disposição cooperativa dos indivíduos em situação nas quais não há neutralidade entre as relações de poder, de tal modo que os compromissos assumidos equilibram os interesses conflitantes.

O trabalho pautado na ação comunicativa, que busca o entendimento entre os sujeitos envolvidos, deve levar em conta tanto as relações entre os traba- lhadores no trabalho em saúde, quanto deles com os usuários/população de referência do serviço, dada a natureza intersubjetiva do trabalho em saúde, referida acima.

[...] a atenção primária é principalmente de prevenção e promoção, ela pode ser menos ou mais curativa. Quanto mais investirmos em aprimoramento para ter mais instrumentos teóricos $e$ práticos, mais conseguiremos exercer o nosso trabalho. Por isso que em uma UBS a gente tem por semana dois períodos de atividades educativas em reuniões, há mais acesso [...] A formação da enfermagem nível médio é hospitalar, é só curativa, a equipe é hierarquizada, então fica muito difícil. Já chega com uma postura de subserviência ao médico que a maioria aqui não tem, porque se a vida inteira discutirmos que vamos trabalhar juntos, que vamos construir juntos, não tem essa subserviência total (T23 - auxiliar de enfermagem).

Os depoimentos ressaltam a importância de espaços educativos em reuniões multiprofissionais. A integração dos trabalhos especializados depende do reconhecimento dos nexos presentes entre as ações de saúde, ou seja, do reconhecimento do trabalho do outro que pressupõe sua concepção do processo saúde-doença. Essa concepção pode ser expressa por meio da integralidade que justifica e motiva os trabalhadores para a proposta do trabalho em equipe em substituição ao trabalho individualizado por profissional, pois para articulação das ações de promoção, prevenção e recuperação da saúde e para a apreensão ampliada das necessidades de saúde dos usuários/população do território é necessário que os trabalhadores atuem de modo articulado e integrado com inserção em um modelo de organização do trabalho voltado a essa lógica (Peduzzi, 2001, 2007).

A integralidade relaciona-se à lógica de organização dos serviços e das práticas de saúde, que preconiza a integração dos serviços assistenciais e de saúde pública com a superação da fragmentação das atividades e horizontalização dos programas de atenção à saúde anteriormente verticais com equipes que pensem em suas práticas a partir das necessidades dos usuários e da população. Assim, amplia as possibilidades de apreensão das necessidades de 
saúde de um grupo populacional na perspectiva do diálogo (Mattos, 2004).

A integralidade remete à superação de fragmentações presentes no cotidiano dos serviços. Pinheiro e Luz (2003) ressaltam a dimensão da integralidade, que considera a interação democrática dos agentes do trabalho no cotidiano de sua prática com questionamentos das relações de saber e poder presentes nas especialidades profissionais e no privilégio à participação de diversos agentes e suas práticas no cotidiano. As autoras consideram que a Estratégia de Saúde da Família (ESF), estratégia da política pública de saúde para a reestruturação da APS, é uma iniciativa inovadora de organização das práticas de saúde voltada para a atenção integral de indivíduos e famílias com o compromisso de mudar o modelo de atenção vigente e romper com a visão biomédica centrada na doença. Essas mudanças ocorrem em quatro principais direções: a atuação em saúde no espaço domiciliar, o resgate de ações de promoção e prevenção da saúde concebida como direito de cidadania, a priorização da formação e da capacitação dos trabalhadores e a busca da satisfação do usuário.

[...] Porque se você pega o SUS, o PSF, o que é preconizado é você considerar a realidade das pessoas, da comunidade, em cima da realidade dos dados, é só estabelecer um plano de trabalho, e a educação deveria reforçar isso daí o tempo todo (T2o - educador).

Alguns relatos ressaltam a importância da EPS e da educação no contexto da realidade de trabalho do ESF. De acordo com a portaria ministerial n. 648/ GM de 28 de março de 2006, as atividades de EPS estão no rol de atribuições mínimas específicas de cada categoria profissional com destaque para sua promoção por médicos, enfermeiros e cirurgiões dentistas (Brasil, 2006).

Reconhecer que a educação é inerente à organização do trabalho em saúde, contudo, não configura um único e homogêneo entendimento das práticas, mas remete para duas concepções distintas de educação e de organização do trabalho em saúde ou modelo assistencial. A primeira é a educação comunicativa/emancipatória com organização do trabalho orientada para a integralidade, trabalho em equipe, gestão comunicativa/participativa. A segunda é a educação instrumental/tradicional com a organização do trabalho orientada pelo modelo biomédico hegemônico, cujo foco é a remissão de sintomas, o trabalho individualizado por profissional e a gestão taylorista/fordista. Segundo Matos e Pires (2006), o modelo de organização do trabalho predominante pressupõe a hierarquização e a fragmentação com a separação entre concepção e execução para o aumento da produtividade no trabalho.

\section{Atividades Educativas de Trabalhadores para Transmitir e Atualizar Informações}

As mudanças no trabalho trazidas pelas transformações no ambiente, por novas tecnologias, mudanças sociais e do perfil epidemiológico da população tornam necessário o desenvolvimento de ações de EC para adequar a formação dos trabalhadores com a realidade prática dos produtos e serviços. Os serviços de saúde e seus trabalhadores precisam acessar constantes e dinâmicos meios de atualização dos conhecimentos. A EC é um meio pertinente por possibilitar a aquisição de conhecimentos técnicocientíficos para a capacitação e o desenvolvimento de trabalhadores de acordo com a realidade social e da instituição (Girade e col., 2006; Bezerra, 200o).

No grupo de entrevistados, alguns depoimentos apresentam a concepção instrumental/tradicional de educação que se aproxima da EC. Esse grupo é representado por: enfermeiro, auxiliar técnicoadministrativo, auxiliar de consultório dentário, técnico de informática, fonoaudiólogo, dentista e assistente social.

Acho que a atividade educativa é fundamental, você tem que estar se atualizando, se reciclando, porque as coisas mudam rapidamente e a gente também tem que ter essas informações ao mesmo tempo, senão fica complicado, acho que tem que ter isso, atualização constante ( $\mathrm{T}_{4}$ - assistente social).

A literatura revela que a EC preconiza a atualização profissional mediante demandas pontuais de desenvolvimento, centradas nas capacitações técnico-científicas, desarticuladas e fragmentadas, frequentemente desvinculadas das necessidades 
de saúde (Peduzzi e col., 2009; Girade e col., 2006; Bezerra, 200o; Davim e col., 1999). Os relatos mostram a importância da EC para assegurar o domínio técnico-científico.

Como discutido anteriormente, a concepção tradicional da educação convive com a concepção emancipatória. No grupo de entrevistados, muitos expressam essa composição da educação no trabalho. Esse resultado é divergente ao que é predominantemente encontrado nos estudos sobre o tema que revelam o destaque para as atividades educativas na perspectiva tradicional/instrumental. Essa diferença pode estar relacionada às características das duas UBS pesquisadas, nas quais se identifica uma tradição consolidada de ações educativas para trabalhadores e atividades para a formação de estudantes de graduação e pós-graduação em saúde por constituírem campos de estágio.

Alguns depoimentos revelam o caráter complementar das concepções tradicional/instrumental e emancipatória/comunicativa. Os depoentes consideram imprescindível o desenvolvimento de atividades voltadas ao rigor técnico-científico veiculado predominantemente em ações educativas tradicionais, na vertente da EC, juntamente com a reflexão sobre as práticas de saúde com a participação dos trabalhadores, usuários e gerentes para a construção coletiva de novos saberes necessários para o trabalho em saúde, característica da EPS.

Para alguns depoentes, as atividades tradicionais estão relacionadas ao saber instrumental presente nas técnicas de saúde, que pressupõem a maneira julgada correta de se executar uma tarefa, fundamentada em princípios cientificamente estabelecidos.

Tem que ter um momento de reflexão e tem que ter um momento de aprofundamento técnico, você ficar só na reflexão, não avança. Tem que ter um momento onde você oferece um algo a mais, aí não precisa ser necessariamente uma aula explicativa, mas de repente um texto bom, uma leitura de um texto que complemente, que fundamente, ou porque não uma aula expositiva, pode ser também? Uma aula expositiva que junte aquilo que ficou pendente pode ser também, não há nenhum problema, o que eu não acho é que a gente não deve rechaçar nenhuma coisa nem outra. Acho que a composição ela é a melhor. Há assuntos, por exemplo, que se você colocar uma aula teórica fica horrivel, o melhor é que seja prática e você vai fazer contextualizando ao fazer. Há coisas que você precisa primeiro refletir para depois aprofundar, então acho que vai muito do assunto, o assunto que vai lhe dizer qual é o melhor caminho, e você ter o mínimo de conhecimento do grupo ( $\mathrm{G}_{5}$ - enfermeiro).

Um depoente ressaltou a dificuldade de se realizar atividades completamente emancipatórias devido à falta de tradição da participação de trabalhadores em espaços de discussão para os quais se sentem inseguros e sujeitos a críticas dos pares. Concomitantemente aponta-se a importância de haver espaços de reflexão alternados com momentos mais normativos para aprofundar os saberes técnicos contextualizados às práticas desenvolvidas no serviço.

\section{Considerações Finais}

A pesquisa mostra o potencial da articulação teórica entre as concepções de processo de trabalho em saúde e a teoria do agir comunicativo, bem como da utilização da EPS e EC como categorias operacionais para a análise do objeto de estudo - a educação de trabalhadores da saúde inseridos no trabalho.

A concepção de educação como construção coletiva pautada no agir comunicativo, contextualizada na realidade de trabalho, predomina na realidade empírica investigada. Essa representação pode ser denominada comunicativa/emancipatória, pois promove a participação e reflexão dos sujeitos partícipes do processo de trabalho, trabalhadores, usuários e gerentes de serviços de saúde e corrobora a concepção de EPS interprofissional. A ação comunicativa presente à educação no trabalho em saúde contribui para ampliar espaços de reflexão sobre as práticas e configurar ações que não sejam reduzidas à racionalidade instrumental que orienta a execução de procedimentos.

A maior parte dos estudos sobre o tema revela o predomínio de concepções e práticas tradicionais em relação à educação no trabalho e à educação em saúde. Nesse sentido, o presente estudo revela significativas diferenças que podem ter sido incorporadas 
às práticas de saúde em duas UBS que se constituem campos de estágio para a formação de estudantes de graduação e pós-graduação em saúde.

Os resultados também apontam para a educação como um elemento inerente à organização do trabalho em saúde, que tanto pode se constituir em um processo de construção coletiva do saber, assinalado acima, como revelar a concepção tradicional de educação enquanto transmissão e atualização de informações.

Nesse sentido, os resultados assinalam que as atividades educativas de trabalhadores da saúde também devem estar voltadas para a atualização técnico-científica dos saberes específicos de cada área profissional. Os relatos destacam a necessidade de discutir o saber instrumental que é pertinente ao desenvolvimento de ações técnicas com resolubilidade.

Assim, as atividades educativas de trabalhadores da saúde na atenção primária são compostas de ações pautadas tanto na concepção comunicativa/ emancipatória de educação quanto na instrumental/ tradicional. 0 que atesta o caráter complementar das abordagens da EPS e EC.

Os resultados apontam para a necessidade de aprofundar a investigação sobre os critérios de reconhecimento da pertinência de cada uma das abordagens, EPS e EC. Também é necessário ampliar a pesquisa em UBS, nas quais a educação no trabalho não esteja estruturada como na realidade investigada, e estudar os efeitos/impactos que a articulação de ações de EPS e EC pode ter na qualidade da atenção aos usuários e no avanço na direção da transformação das práticas de saúde na APS.

\section{Referências}

ALVES, V. S. Um modelo de educação em saúde para o programa de saúde da família: pela integralidade da atenção e reorientação do modelo assistencial. Interface, Comunicação, Saúde, Educação, Botucatu, v. 6, n. 9, p. 39-52, 2005.

ARAGÃO, L. Habermas: filósofo e sociólogo do nosso tempo. Rio de Janeiro: Tempo Brasileiro, 2002.
ARTMANN, E. Interdisciplinaridade no enfoque intersubjetivo habermasiano: reflexões sobre planejamento e Aids. Ciência \& Saúde Coletiva, Rio de Janeiro, v. 6, n. 1, p. 183-195, 2001.

BARDIN, L. Análise de conteúdo. Lisboa: Edições 70, 2009.

BEZERRA, A. L. Q. O contexto da educação continuada em enfermagem na visão dos gerentes de enfermagem e dos enfermeiros de educação continuada. Mundo Saúde, São Paulo, v. 24, n. 5, p. 352-356, 2000

BRASIL. Ministério da Saúde. Resolução n. 196, de 10 de outubro de 1996. Estabelece normas de pesquisa envolvendo seres humanos. Brasília: Ministério da Saúde, 1996.

BRASIL. Mnistério da Saúde. Portaria n. 648, de 28 de março de 20o6. Aprova a Política Nacional de Atenção Básica, estabelecendo a revisão de diretrizes e normas para a organização da Atenção Básica para o Programa Saúde da Família (ESF) e o Programa Agentes Comunitários de Saúde (PACS). Brasília: Ministério da Saúde, 2006.

CECCIM, R. B.; FEUERWERKER, L. C. M. Mudança na graduação das profissões de saúde sob o eixo da integralidade. Cadernos de Saúde Pública, Rio de Janeiro, v. 20, n. 5, p. 1400-1410, 2004.

CECCIM, R. B. Educação permanente em saúde: desafio ambicioso e necessário. Interface, Comunicação, Saúde, Educação, Botucatu, v. 9, n. 16, p. 161-168, 2005a.

CECCIM, R. B. Educação permanente em saúde: descentralização e disseminação de capacidade pedagógica na saúde. Ciência \& Saúde Coletiva, Rio de Janeiro, v. 10, n. 4, p. 975-986, 2005b.

COOK, T. D.; REICHARDT, C. H. S. Métodos cualitativos y cuantitativos em investigación evaliativa. 4. ed. Madrid: Ediciones Morata, 2000.

DAVIM, R. M. B. ; TORRES, G. V.; SANTOS, S. R. Educação continuada em enfermagem: conhecimentos, atividades e barreiras encontradas em uma maternidade escola. Revista Latino-Americana de Enfermagem, Ribeirão Preto, v. 7, n. 5, p. 43-50, 1999. 
FEUERWERKER, L. Educação permanente em saúde: uma mudança de paradigmas. Olho Mágico, Londrina, v. 12, n. 3, p. 13-20, 2005.

FREIRE, P. Pedagogia do oprimido. 47. ed. Rio de Janeiro: Paz e Terra, 2005.

GIRADI, M. G.; CRUZ, E. M. N.; STEFANELLI, M. C. Educação continuada em enfermagem psiquiátrica: reflexão sobre conceitos. Revista da Escola de Enfermagem da USP, São Paulo, v. 4o, n. 1, p. 106-110, 2006.

HABERMAS, J. Técnica e ciência como ideologia. Lisboa: Edições 70, 1994.

HABERMAS, J. Teoria de la acción comunicativa: racionalidad de la acción y racionalización social. Madrid: Taurus; 2001.

LIMA, M. A. D. S.; ALMEIDA, M. C. P. O trabalho de enfermagem na produção de cuidados de saúde no modelo clínico. Revista Gaúcha de Enfermagem, Porto Alegre, v. 20, (n. esp.), p. 86-91, 1999.

LOPES, N. M. Recomposição profissional da enfermagem. Coimbra: Quarteto Editora, 2001.

MATOS, E.; PIRES, D. Teorias administrativas e organização do trabalho: de Taylor aos dias atuais, influências no setor saúde e na enfermagem. Texto \& Contexto Enfermagem, Florianópolis, v. 15, n. 3, p. 508-514, 2006.

MATTOS, R. A. A integralidade na prática ou sobre a prática da integralidade. Cadernos de Saúde Pública, Rio de Janeiro, v. 20, n. 4, p. 1411-1416, 2004.

MEIRELLES D. S. O conceito de serviço. Revista de Economia Política, São Paulo, v. 26, n. 1, p.119-136, 2006.

MERHY, E. E.; FEUERWERKER, L. C. M.; CECCIM, R. B. Educación permanente em salud: uma estratégia para intervir na micropolítica del trabajo em salud. Salud Colectiva, Buenos Aires, v. 2, n. 2, p. 147-16o, 2006.

OFFE, C. Capitalismo desorganizado. São Paulo: Brasiliense; 1995.

PEDUZZI, M. Equipe multiprofissional de saúde: conceito e tipologia. Revista de Saúde Pública, São Paulo, v. 35, n. 1, p. 103-109, 2001.
PEDUZZI, M. Mudanças tecnológicas e seu impacto no processo de trabalho em saúde. Trabalho Educação e Saúde, Rio de Janeiro, v. 1, n. 1, p. 75-91, 2002.

PEDUZZI, M. Trabalho em equipe de saúde no horizonte normativo da integralidade, do cuidado e da democratização das relações de trabalho. In: PINHEIRO, R.; BARROS, M. E. B.; MATTOS, R. A. Trabalho em equipe sob o eixo da integralidade: valores, saberes e práticas. Rio de Janeiro: IMES/ UERJ, CEPESC, ABRASCO, 2007. p. 33-46.

PEDUZZI, M. et al. Atividades educativas de trabalhadores na atenção primária: concepções de educação permanente e de educação continuada em saúde presentes no cotidiano de unidades básicas de saúde em São Paulo. Interface, Comunicação, Saúde e Educação, Botucatu, v. 13, n. 30, p. 121-134, 2009.

PINHEIRO, R.; LUZ, M. T. Práticas eficazes versus modelos ideais: ação e pensamento na construção da integralidade. In: PINHEIRO, R.; MATTOS, R. A. (Orgs.). Construção da integralidade: cotidiano, saberes, práticas em saúde. Rio de Janeiro:

ABRASC0, 2003. p. 7-34.

PINHEIRO, R. Integralidade em Saúde. In: ESCOLA POLITÉCNICA DE SAÚDE JOAQUIM VENÂNCIO; ESTAÇÃO DE TRABALHO OBSERVATÓRIO DE TÉCNICOS EM SAÚDE. Dicionário da educação profissional em saúde. Rio de Janeiro: Fiocruz, 2006. p. 159-166.

PIRES, D.; GELBCKE, F. L.; MATOS, E. Organização do trabalho em enfermagem: implicações no fazer e viver dos trabalhadores de nível médio. Trabalho, Educação e Saúde, Rio de Janeiro, v. 2, n. 2, p. 311325, 2004 .

RAMOS, M. Educação pelo trabalho: possibilidades, limites e perspectivas da formação profissional. Saúde e Sociedade, São Paulo, v. 18, sup. 2. p. 55-59, 2009.

ROCHA, S. M. M.; ALMEIDA, M. C. P. O processo de trabalho da enfermagem em Saúde Coletiva e a interdisciplinaridade. Revista Latino-Americana de Enfermagem, Ribeirão Preto, v. 8, n. 6, p. 96-101, 2000 . 
SCHRAIBER, L. B. et al. Planejamento, gestão e avaliação em saúde: identificando problemas.

Ciência \& Saúde Coletiva, Rio de Janeiro, v. 4, n. 2, p. 221-42, 1999.

SCHRAIBER, L. B. A pesquisa qualitativa em saúde: reflexões metodológicas do relato oral e produção de narrativas em estudo sobre a profissão médica. Revista de Saúde Pública, São Paulo, v. 29, n. 1, p. 63-74, 1995.

SILVA, J. A. M. Análise das atividades educativas de trabalhadores de saúde na atenção básica: concepções de educação no trabalho, levantamento de necessidades, público participante e resultados esperados. 2009.

Dissertação (Mestrado em Enfermagem) - Escola de Enfermagem, Universidade de São Paulo, São Paulo, 2009.

SOUZA, A.; ROSCHKE, M. A. Educación continua y aprendizaje a lo largo de la vida: valoración de sus contribuciones para el desempeño individual e organizacional. Caderno, Currículo e Ensino, Rio de Janeiro, v. 6, n. 3, p. 7-29, 2003. 